\title{
Sri Lanka Association of Urological Surgeons
}

Fifth Annual Academic Sessions of the Sri Lanka Association of Urological Surgeons was held on 10th and 11th December, 2010 at Hotel Taj Samudra, Colombo.

Pre-congress workshops were held in the run-up to the main conference:

1. Postgraduate Course in Percutaneous Nephrolithotomy was conducted at the National Hospital of Sri Lanka and Asiri Surgical Hospital on 6th to 8th December under the supervision of two eminent urological surgeons, Mr Graham Watson, from Eastbourne, United Kingdom and Dr Janak Desai, from Ahmadabad, India.

2. Minimally invasive urology: where do we stand? - a video presentation and discussion on open, endoscopic and laparoscopic urology practiced in Sri Lanka

This workshop was held on 3rd December 2010 at the Department of Surgery Lecture Theatre, NHSL, Colombo.

3. Hands-on workshop on the management of bladder and ureteric injuries was held on 10th December at the Skills Laboratory, University Department of Surgery, Colombo South Teaching Hospital (organized by Dr Srinath Chandrasekera).

4. Workshop for Urology and Surgical Nurses, organized by Dr Susantha de Silva and Dr Dimantha de Silva was a well attended, successful event (held on 3rd December at the Surgery Auditorium of the NHSL).

At the inauguration of sessions with Secretary of Health, Dr T. R. C. Ruberu, as the Chief Guest, and Dr L. S. Attygalle, as Guest of Honour, the SLAUS Lecture was delivered by Dr M. V. Kochikar, Chief Uro-oncologist, Siddhi Vinayak Ganapathi Cancer Hospital, Miraj, Maharashtra, India, entitled "Progress in renal cancer - a journey that Czerny started"

Honorary Fellowships were bestowed on Dr Lakshman Sujeeva Attygalle and Mr Graham Michael Watson.

Presidential Address was delivered by Prof. Neville D. Perera. He briefly explained the technical and manpower development in urology in this country and spoke on renaissance of Sri Lankan urology in great length. He elaborated on the problems faced by urologists returning after overseas training and possible solutions to them. 
Fifth Annual Academic Sessions of the SLAUS

$10^{\text {th }}$ and $11^{\text {th }}$ December 2010
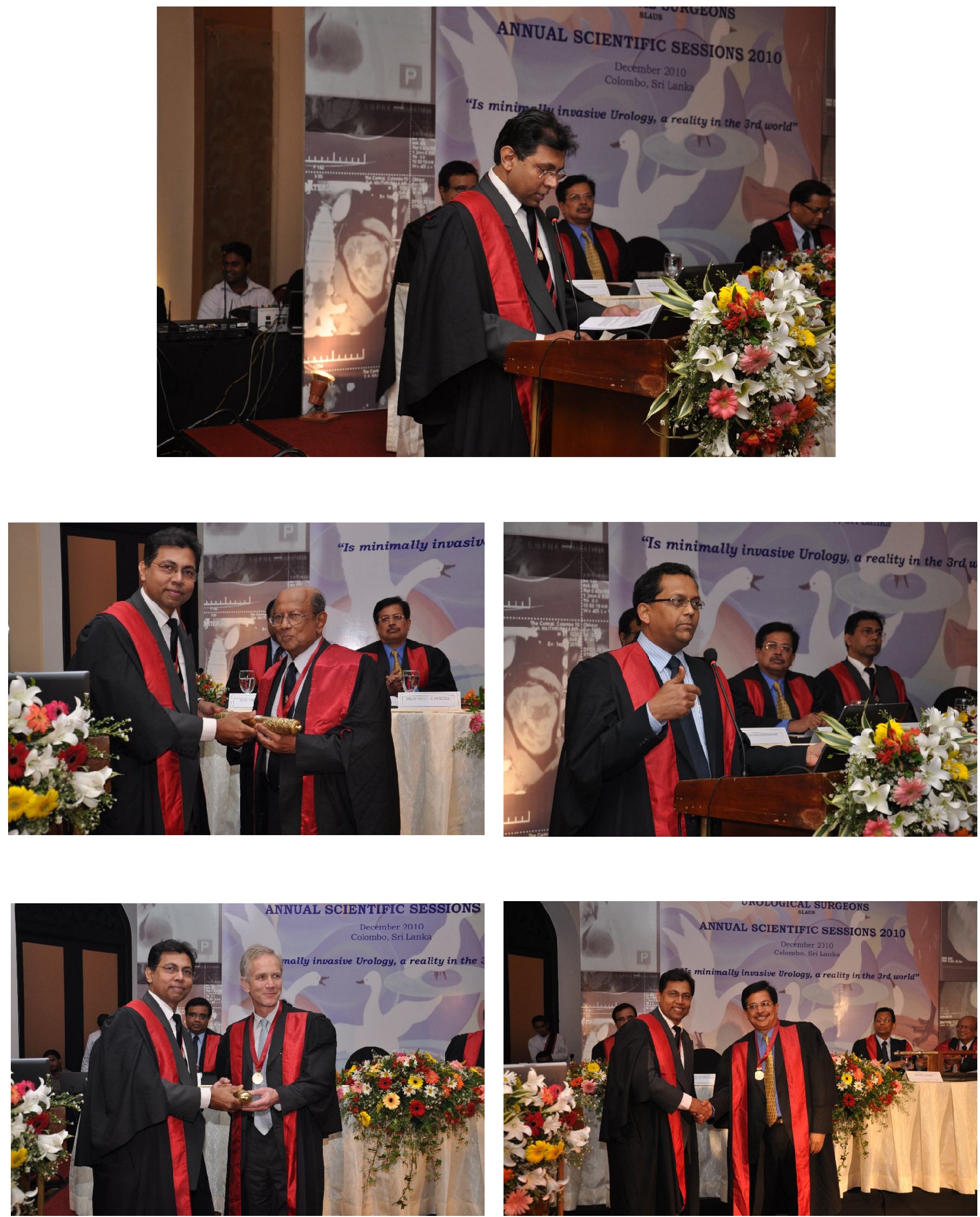